\title{
Correction
}

\section{Correction: Braga et al. Cyclodextrins in Antiviral Therapeutics and Vaccines. Pharmaceutics 2021, 13, 409}

\author{
Susana Santos Braga ${ }^{1, * \mathbb{D}}$, Jéssica S. Barbosa ${ }^{1,2} \mathbb{D}$, Nádia E. Santos ${ }^{1} \mathbb{D}$, Firas El-Saleh ${ }^{3}(\mathbb{D})$ \\ and Filipe A. Almeida Paz 2 (D) \\ 1 LAQV-REQUIMTE, Department of Chemistry, University of Aveiro, 3810-193 Aveiro, Portugal; \\ jessicambarbosa@ua.pt (J.S.B.); nadiaasantos@ua.pt (N.E.S.) \\ 2 CICECO-Aveiro Institute of Materials, Department of Chemistry, University of Aveiro, \\ 3810-193 Aveiro, Portugal; filipe.paz@ua.pt \\ 3 Ashland Specialty Ingredients, Paul-Thomas Strasse, 56, D-40599 Düsseldorf, Germany; \\ FElSaleh@ashland.com \\ * Correspondence: sbraga@ua.pt
}

check for updates

Citation: Braga, S.S.; Barbosa, J.S.; Santos, N.E.; El-Saleh, F.; Paz, F.A.A. Correction: Braga et al. Cyclodextrins in Antiviral Therapeutics and Vaccines. Pharmaceutics 2021, 13, 409. Pharmaceutics 2022, 14, 499. https:// doi.org/10.3390/pharmaceutics 14030499

Received: 26 November 2021 Accepted: 16 February 2022 Published: 24 February 2022

Publisher's Note: MDPI stays neutral with regard to jurisdictional claims in published maps and institutional affiliations.

Copyright: () 2022 by the authors Licensee MDPI, Basel, Switzerland. This article is an open access article distributed under the terms and conditions of the Creative Commons Attribution (CC BY) license (https:// creativecommons.org/licenses/by/ $4.0 /)$.

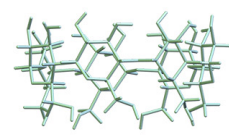

$\beta-C D$

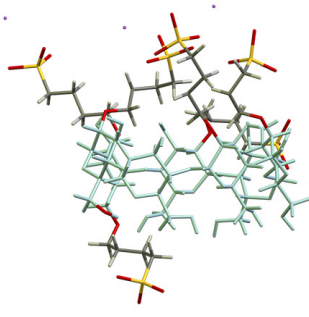

SBE $\beta C D$

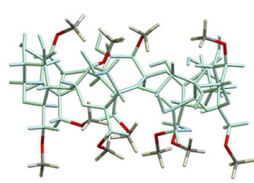

RAMEB

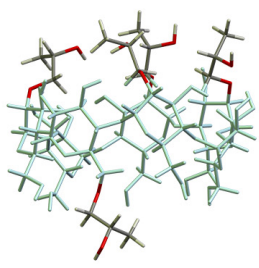

HPßCD
Figure 2. Structural representation of $\beta-C D$ and three of its derivatives: (2-hydroxy)propyl-betacyclodextrin (HP $\beta C D)$, randomly methylated beta-cyclodextrin (RAMEB), and sulfobutyl ether $\beta-C D(S B E \beta C D)$. The main skeleton of $\beta-C D$ is represented in blue and the substituent groups are highlighted with different colours (carbon in grey, oxygen in red, hydrogen in white, sulphur in yellow and sodium in purple).

The authors apologise for any inconvenience caused and state that the scientific conclusions are unaffected. The original publication has also been updated.

\section{Reference}

1. Braga, S.S.; Barbosa, J.S.; Santos, N.E.; Hyun, S.M.; El-Saleh, F.; Paz, F.A.A. Cyclodextrins in Antiviral Therapeutics and Vaccines. Pharmaceutics 2021, 13, 409. [CrossRef] [PubMed] 